

\title{
Gênero, educação e literatura
}

\author{
Maria Arisnete Câmara de Morais
}

MACHADO, CJS., SANTIAGO, IMFL., and NUNES, MLS., orgs. Gêneros e práticas culturais: desafios históricos e saberes interdisciplinares [online]. Campina Grande: EDUEPB, 2010. 256 p.



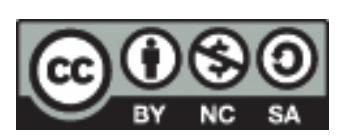

All the contents of this work, except where otherwise noted, is licensed under a Creative Commons Attribution-Non Commercial-ShareAlike 3.0 Unported.

Todo o conteúdo deste trabalho, exceto quando houver ressalva, é publicado sob a licença Creative Commons Atribuição Uso Não Comercial - Partilha nos Mesmos Termos 3.0 Não adaptada.

Todo el contenido de esta obra, excepto donde se indique lo contrario, está bajo licencia de la licencia Creative Commons Reconocimento-NoComercial-CompartirIgual 3.0 Unported. 
Gênero, educação e literatura 


\title{
Gênero, educação e literatura
}

\author{
Maria Arisnete Câmara de Morais
}

Para este colóquio sobre gênero educação e literatura gostaria de me debruçar sobre as leituras de formação, que regulam condutas e modos de ser nas relações de poder entre os sexos, estabelecidos na sociedade de fins do século XIX. Falo das escritoras Isabel Gondim e Ana Ribeiro de Góes Bettencourt. Uma natalense e a outra baiana.

Inicialmente, debruço-me sobre o livro Reflexões às minhas alunas, de autoria da norte-rio-grandense Isabel Gondim (1839-1933).

Esse livro teve bastante aceitação de público, considerando o número das edições como parâmetro de julgamento. Editou-se esse livro três vezes. A primeira edição, publicada no Rio de Janeiro, em 1874 e a segunda, com uma tiragem de cinco mil exemplares, editada, também, no Rio de Janeiro, pela Tipografia Popular, em 1879. A terceira edição foi revista e aumentada, impressa em Natal, pela Tipografia A. Leite, em 1910. Seu conteúdo de cunho pedagógico, aplicado a determinados usos específicos, proporciona uma linha segura e permanente de vendas, justificando, talvez, a sua popularidade.

O objetivo é apenas a análise de parte desta obra, dada a sua importância para a historiografia da educação no Brasil, durante as últimas décadas do 
século XIX e início do século XX. Principalmente no que trata acerca das relações de gênero e o papel que cabe à mulher representar nesse contexto.

A escritora orienta as jovens sobre noções básicas do convívio em sociedade e mostra, entre outros, os deveres para com Deus, deveres para consigo mesma, deveres para com seus semelhantes, seus pais e pessoas da família; enaltece a virtude, que consiste em fazer o bem sem esperança de recompensa; a civilidade, que significa atenção obsequiosa, o que é sinal característico de boa educação e predispõe a todos os que observam essa delicadeza e urbanidade em favor de quem a pratica.

Nesse livro, a escritora oferece às moças alguns conselhos de como se portar na sociedade, através de atitudes e comportamentos dignos de uma jovem bem educada. Para Isabel Gondim, a civilidade revela-se nas palavras, nas ações e nos movimentos.

Esse livro é um manual de conduta, repleto de orientações ao sexo feminino, abordando temas como: a menina escolar, a moça em sua puberdade, a moça em sua juventude ou nubilidade, a mulher casada e a mulher mãe. Para todas essas fases da vida da mulher, a escritora faz reflexões especiais.

Para a menina escolar, ela lembra que a candura e a inocência são os principais atributos dessa quadra de encantos. O conhecimento e o amor a Deus realçam os atrativos dessa pouca idade (GONDIM, 1910, p. 12).

Para a moça em sua puberdade, ela sugere que busque o cultivo das belas artes, especialmente a música que exerce tão poderosa influência sobre a nossa alma. A moça em sua puberdade deve cultivar também as línguas estrangeiras, como a italiana, a inglesa, a alemã e, especialmente, a francesa, em que estão escritas excelentes obras da literatura, ciência e educação. A leitura de bons livros está entre as suas reflexões. A moça deve se acercar de cuidados para não ler obras consideradas perniciosas (GONDIM, 1910, p. 24).

Os romances realistas são "incendiários do coração da mocidade, cujas paixões dissimuladamente exaltam por meio das fantásticas criações de personagens desmoralizados postos em evidência, sob as mais belas e atraentes formas" (GONDIM, 1910, p. 25).

Antes de empreender a leitura de obras desse gênero, a moça deve ouvir a opinião das pessoas sensatas. Talvez a opinião dela própria, a escritora Isabel Gondim. 
Ela lembra que em casa, a jovem não deve escolher um lugar nem pouco recatado nem assento brando como a rede. A rede influi consideravelmente nos órgãos que constituem nosso corpo, trazendo fraqueza ou inação quando dela nos servimos com frequência (GONDIM, 1910, p. 27). As pessoas que adotam esse modo de viver na prática cotidiana perdem a energia e podem tornar-se apáticas. Se esse mau hábito juntar-se ao de embalar com frequência, muitas vezes o corpo se entorpece.

O comportamento nos bailes deve ser impecável. Tratar com polidez e urbanidade a todos que fizerem parte do mesmo ambiente é a regra. Jamais descuidar da civilidade em ambiente público (GONDIM, 1910, p. 33).

Enfim, o recolhimento doméstico e o emprego nas ocupações que se lhes oferecem devem merecer preferência à moça honesta e discreta. Quando recolher-se ao aposento destinado ao dormitório, deve mudar de roupa com recato. Ter todo o cuidado na disposição do cobertor, de modo a ficar decentemente composta.

Para a moça em sua juventude ou nubilidade, sugere que ela não procure nas modas afetadas e muitas vezes ofensivas à moral e à saúde um falso atavio à fisionomia. Não se deixe levar pelos elogios (GONDIM, 1910, p. 37).

A escolha do consorte pode e deve ser confiada a alguém que transpondo a acanhada esfera social de uma pudica donzela tenha adquirido o conhecimento preciso para antever a conveniência da união. A escolha do consorte, porém, compete somente ao homem que, a par da sociedade tenha infiltrado no peito sentimentos de respeitosa simpatia, pelos quais fosse induzido a fazer essa escolha (GONDIM, 1910, p. 40).

Os laços matrimoniais são indissolúveis. Portanto, para contraí-los se faz necessária a maior prudência e circunspeção, que dirijam a uma escolha acertada. Cautela, pois, para:

1- na idade senil, o homem não poderá fazer a completa felicidade da família de que venha constituir-se chefe; por mais vantajosa que pareça a sua união a mulher núbil deverá rejeitá-la;

2- o homem dissoluto, impudente, arrebatado e de maus costumes é detestado por toda a sociedade moralizada que o evita. Como não será a família, a quem terá de dirigir? 
Nesse contexto do início do século XX, referente a melhor escolha que uma moça poderia fazer para contrair núpcias, Lima Barreto (1956) tinha uma preocupação que vinha de encontro com a escritora norte-rio-grandense. No romance Clara dos Anjos, a personagem com o homônimo do livro, uma moça pobre e de cor, sofre as consequências por, apaixonada, entregar-se a Cassi Jones, um rapaz de estratificação pequeno-burguesa, que a engana com declarações de amor, para logo depois de conseguir seu intento, abandoná-la. O narrador, no final do romance, enfatiza que a desdita de Clara foi motivada pela educação recebida:

A educação que recebera de mimos e vigilâncias, era errônea. Ela devia ter aprendido da boca dos seus pais que a sua honestidade de moça e de mulher tinha todos por inimigos, mas isto ao vivo, com exemplos, claramente... [...] (BARRETO, 1956, p. 196)

Retomando Isabel Gondim. Para a mulher casada, ela lembra que os seus destinos não lhe pertencem, desde que assumira esse estado. Ela deverá, portanto, dedicar-se inteiramente àquele que tem superioridade sobre seus destinos. O respeito e o amor mais dedicado ao vosso consorte, a escrupulosa compostura em sua presença, o maior desvelo por tudo o que possa interessarlhe particularmente devem atrair vosso coração e assíduos cuidados.

Entretanto, se a jovem tiver a desventura de encontrar um péssimo marido, que olvide os deveres de fidelidade, amor e respeito, ela não deve dar a conhecer o natural ressentimento. $\mathrm{O}$ conselho é: redobrai de atenções para com esse imponderado consorte (GONDIM, 1910, p. 50).

O conselho de Isabel Gondim é a resignação. Suportar o procedimento do marido e não buscar a represália, que é imprópria das almas generosas. Dissimule suas faltas. Quem sabe talvez consiga transformá-lo no chefe perfeito da casa e da família. É o pensamento da escritora: "Assim, minhas filhas, foi estabelecida a sociedade doméstica que encerra tantos e tão amenos atrativos, e na qual a mulher sensata poderá prestar relevantes serviços ao gênero humano" (GONDIM, 1910, p. 54).

Finalmente, para a mulher mãe, Isabel Gondim aconselha a leitura de obras sobre educação, que muito pode auxiliar na tarefa de educar os pequeninos seres sob a sua responsabilidade. Livros de autores como Almeida Garrett, Jean Jacques Rousseau apresentam considerações dignas de séria atenção, 
principalmente para a mulher mãe, primeira educadora dos seus filhos. "A educação é o que constitui a formação moral do homem; aperfeiçoa as faculdades, impele as suas ações para o bem e molda-lhe o procedimento durante a vida, formando-lhe o caráter" (GONDIM, 1910, p. 54).

Com este entendimento, Isabel Gondim mostra o papel que a mulher mãe desempenha na sociedade, responsável que é pela primeira fase da formação do caráter de seus filhos e a sua carreira na sociedade "em cujo meio serão tanto mais considerados, quanto melhor lhes tenha sido a educação" (GONDIM, 1910, p. 66).

Observamos, através dos prefácios deste livro, que a própria Isabel Gondim escreveu, o empenho da escritora com a integridade da obra e as formas de apropriação do seu conteúdo pelas jovens, seu público preferido. Havia a preocupação em corrigir as imperfeições observadas nos textos, pensando, naquelas leitoras para quem se destinavam esses escritos.

Neste aspecto, reside a modernidade de seu pensar e agir. A preocupação com a instabilidade da obra ao atravessar gerações, em diferentes comunidades de leitores e leitoras. Interrogar-se sobre a história da transmissão dos textos não é simplesmente uma questão bibliográfica, mas também as significações históricas, estéticas e culturais, a partir mesmo da sua materialidade.

Quanto à escritora Ana Ribeiro de Góes Bettencourt (1885), a preocupação fundamental era com a leitura de romances. Ela escrevia no Novo Almanaque de Lembranças Luso - Brasileiro e dirigia-se às senhoras brasileiras e portuguesas alertando-as para o perigo dessas leituras de conteúdo duvidoso: os romances. A escritora reconhece que muitas mulheres têm escrito romances (embora não cite exemplos) bastante aplaudidos; entretanto, explica que elas não tinham em mira instruir, nem moralizar a mocidade de seu sexo e sim granjear um nome na literatura.

Salienta que com os livros que ela mesma escreveu A filha de Jephté e o Anjo do perdão procurou dar um impulso a este gênero de romance; todavia faltou-lhe habilitação e tempo. Apelava então para as escritoras, suas companheiras, que trilhassem esta senda e estariam concorrendo para o engrandecimento do nosso sexo, ampliando a instrução e a moralidade. Em sua opinião, cumpre às mulheres que conhecem mais do que os homens o coração 
feminino, escrever romances para a mocidade, em vez de gastar tempo em fúteis passatempos. A escritora (indignada?) escrevia que

Muitos falam contra os romances como leitura prejudicial à mocidade e pouco proveitosa como fonte de conhecimento. Porém, apesar de quanto se tem dito, continuam eles a ser lido ainda pela maior parte daqueles que reconhecem sua pouca importância, e formam quase exclusivamente a biblioteca das senhoras que dedicam algumas horas à leitura, não se contentando em cuidar somente de modas e enfeites. O que fazem portanto aquelas que não querem restringir-se à vida insípida e material de dona de casa? Pegam em um romance e procuram uma agradável distração enquanto o corpo descansa. Infelizmente porém o que elas muitas vezes aí encontram, são perigosas teorias que matam os sãos princípios de moral que beberam nas sábias lições maternas; terríveis paradoxos, confirmados por fatos imaginários, que se apresentando com os arrebiques dados por hábeis pincéis, e vistos à luz fantástica de uma imaginação exaltada, facilmente seduzem um espírito inexperiente (BETTENCOURT, 1885, p. 62-67).

A escritora Ana Ribeiro de Góes Bettencourt era uma leitora bastante informada. Apesar de apontar a leitura do romance como prejudicial à mocidade, mais especificamente às mulheres, essa leitora conhecia todos os romances que ela mesma execrava. Passeava pela literatura brasileira, portuguesa e francesa com bastante propriedade. Em sua opinião, Alexandre Dumas, Eugène Sue, Ponson du Terrail, Montepin, Alexandre Herculano e José de Alencar eram escritores cujas leituras seduziam as almas inexperientes das leitoras do século XIX. Para ela, José de Alencar, "nosso ameno romancista", é em geral um escritor sério; porém quando descreve a vida selvagem, representa cenas um pouco desnudas e cria perfis de mulheres "altivas e caprichosas". Uma alusão, talvez, aos romances Diva e Lucíola, que eram prejudiciais também. Imagine! Se as mulheres quisessem imitar esses tipos inconvenientes na vida real!

Assim, Isabel Gondim e Ana Ribeiro configuram a historicidade dos seus textos, a publicação, as edições e o momento histórico da educação no Brasil, durante as últimas décadas do século XIX. É próprio da época o culto da rigidez nos movimentos, principalmente para a mulher. Culto que se observa até nas orientações quanto à roupa de dormir, no pudor, no extremo recato diante do marido. Compostura e decência, palavras corriqueiras para os códigos de moral que prevalecem, a interdição da nudez exposta, mesmo na vida privada. 
De não se permitir sonhar languidamente numa rede. O perigo de tornar-se apática, predisposta a práticas, talvez perniciosas para as convenções dos tempos. O autoconhecimento do corpo, da manipulação efetiva.

A repressão do corpo, a repressão dos devaneios. São lições que estas escritoras tentam passar às suas alunas e leitoras, sendo elas mesmas mulheres aprisionadas no seu próprio corpo e todas são vítimas de uma sociedade que as estigmatiza.

A história da vida privada era algo ainda indevassável. Um outro eu que se constituía. O que existia mesmo eram ditames de conduta para as mulheres, que são exemplos de domesticação do corpo e da alma, atrelados a uma teoria que relativiza a inteligência feminina. Igualdade de gênios, de condição, de fortuna e de idade são supostos parâmetros que detectam a harmonia entre os sexos.

\section{Referências}

BARRETO, Lima. Clara dos Anjos. São Paulo: Brasiliense, 1956.

BETTENCOURT, D. Ana Ribeiro de Góes. O romance: às senhoras portuguesas e brasileiras. In: NOVO ALMANAQUE DE LEMBRANÇAS LUSO-BRASILEIRO PARA O ANO DE 1886. Lisboa: António Maria Pereira, 1885.

GONDIM, Isabel. Reflexões às minhas alunas. 3. ed. Natal: Tipografia de A. Leite, 1910.

A lira singela. Rio de Janeiro: Imperial Duco, 1933.

O preceptor. Recife: Imprensa Industrial, 1923.

O Brasil: poema histórico do país. 2. ed. Rio de janeiro: Papelaria Americana, 1913.

. O sacrifício do amor. Drama em cinco atos. Rio de Janeiro: tipografia e Litografia Comercial, 1909.

Norte. Natal: Tipografia da gazeta do Comércio, 1908. 
Elementos de educação escolar: para uso nas escolas primárias de um e outro sexo. Manuscrito, 1885.

MORAIS, Maria Arisnete Câmara de. Isabel Gondim, uma nobre figura de mulher. Natal: Terceirize, 2003. (Série Educação e Educadores do Rio Grande do Norte. V.1. Coleção Mossoroense).

A escritora Isabel Gondim e a história da educação. In:

AMARILHA, Marly (Org.). Educação e leitura, trajetórias de sentido. João Pessoa: UFPB, 2003, p. 245-261. 